
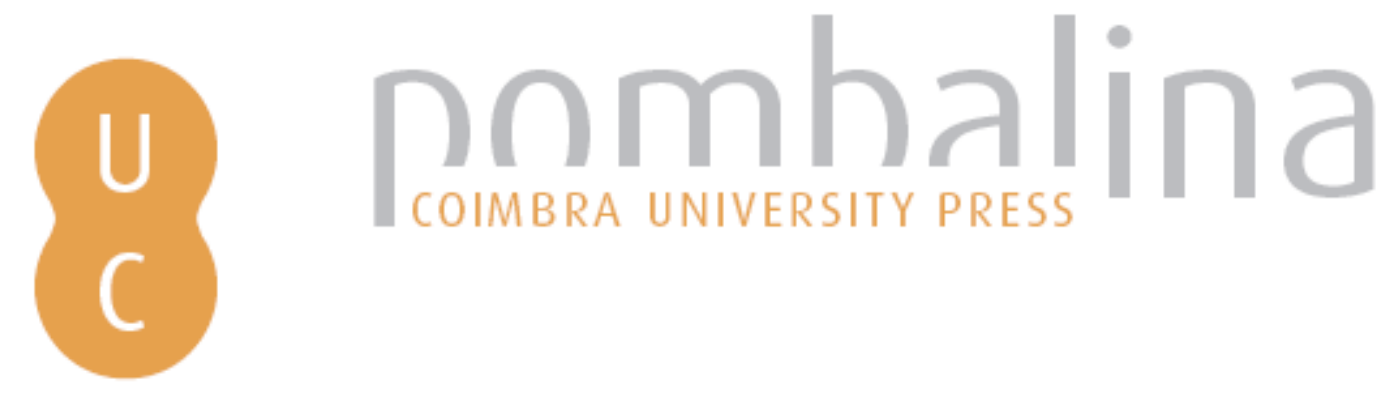

O romance de Carite em Apuleio: trágica admonição da providência
Autor(es):
Brandão, José Luís Lopes
Publicado por: Centro de Estudos Clássicos e Humanísticos
URL persistente:
URI:http://hdl.handle.net/10316.2/39254
DOI:
DOI:http://dx.doi.org/10.14195/978-989-26-1229-4_12

Accessed : $\quad$ 26-Apr-2023 01:26:06

A navegação consulta e descarregamento dos títulos inseridos nas Bibliotecas Digitais UC Digitalis, UC Pombalina e UC Impactum, pressupõem a aceitação plena e sem reservas dos Termos e Condições de Uso destas Bibliotecas Digitais, disponíveis em https://digitalis.uc.pt/pt-pt/termos.

Conforme exposto nos referidos Termos e Condições de Uso, o descarregamento de títulos de acesso restrito requer uma licença válida de autorização devendo o utilizador aceder ao(s) documento(s) a partir de um endereço de IP da instituição detentora da supramencionada licença.

Ao utilizador é apenas permitido o descarregamento para uso pessoal, pelo que o emprego do(s) título(s) descarregado(s) para outro fim, designadamente comercial, carece de autorização do respetivo autor ou editor da obra.

Na medida em que todas as obras da UC Digitalis se encontram protegidas pelo Código do Direito de Autor e Direitos Conexos e demais legislação aplicável, toda a cópia, parcial ou total, deste documento, nos casos em que é legalmente admitida, deverá conter ou fazer-se acompanhar por este aviso.

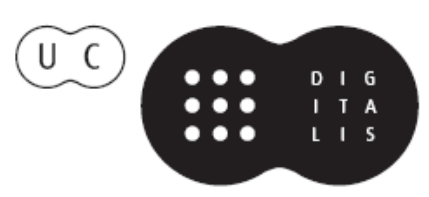


FRANCISCO DE OLIVEIRA

PAOLO FEDELI

DELFIM LEÃO

Coordenadores

\section{- ROMANCE ANTIGO ORIGENS DE UM GÉNERO LITERÁRIO}

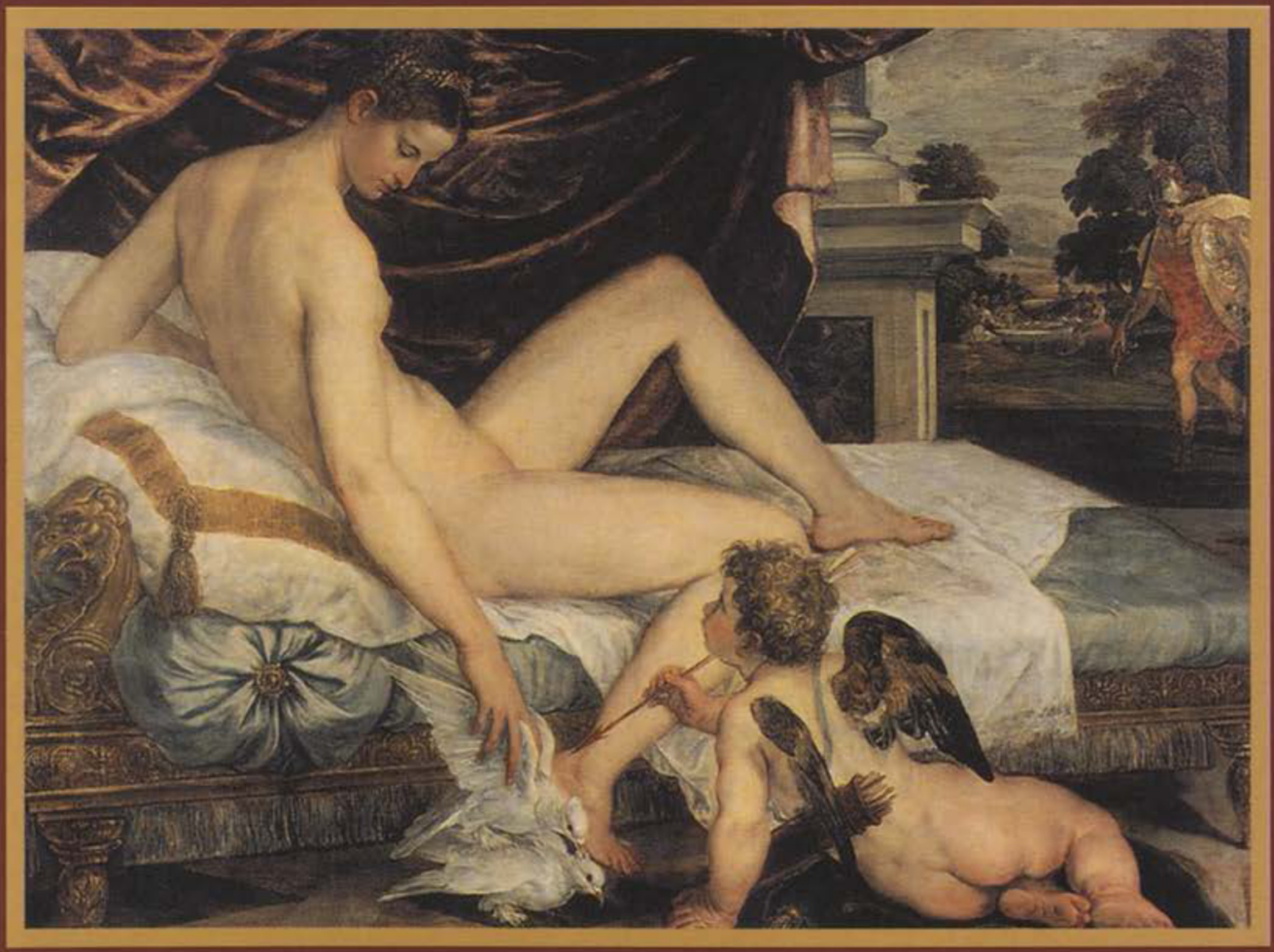

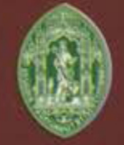

Universidade de Coimbra

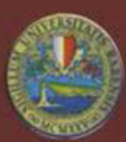

Università degli Studi di Bari

COIMBRA

2005 


\title{
O ROMANCE DE CÁRITE EM APULEIO: Trágica admonição da providência
}

\author{
JOSÉ LUIS LOPES BRANDÃO \\ Universidade de Coimbra
}

\begin{abstract}
Charite's story, in the Metamorphoses of Apuleius, reveals several tragic elements, such as the structure, the passage from happiness to misfortune, the strong presence of tyche (represented in the romance by the Fortuna caeca), a kind of hamartia, the progression to the catastrophe and the two oneiric experiences. Charite's dreams find a parallel in Aeschylus, Sophocles and especially in Euripides' tragedies. In the second dream, Tlepolemus himself discloses to his wife the crime in which he was the victim. This situation recalls the ghost of Polidorus, in Euripides' Hecuba, by the contents, by the kind of reactions caused in the protagonist, and by the process of revenge culminating in the act of blinding the murderer.

If we accept the apologetic intention of the romance, Charite's tragedy reveals moralizing and religious purposes (as suggested by the speech of Isis' priest in 11.15), supported by the hope in liberation from the oppression of the Fortuna and in a post mortem redemption.
\end{abstract}

Nec tibi natales ac ne dignitas quidem, uel ipsa, qua flores, usquam doctrina profuit, sed lubrico uirentis aetatulae ad seruiles delapsus uoluptates curiositatis inprosperae sinistrum praemium reportasti ${ }^{1}$.

'Nem a tua origem, nem sequer a condição social, e nem mesmo a ciência, em que és ilustrado, te valeram de nada; mas, por causa dos deslizes de uma juventude pujante, decaiste em prazeres servis, e obtiveste a funesta recompensa de uma curiosidade malfadada'.

${ }^{1}$ Apuleio, Met. 11.15. Usamos o texto estabelecido por RoBERTSON, D. S., e traduzido por Vallette, P., Paris, Les Belles Lettres, 1985. Aqui deixo expresso o meu sincero agradecimento a Walter de Medeiros, Maria do Céu Fialho, Cláudia Teixeira, Cláudia Cravo e Susana Marques pelas sugestões quer bilbiográficas, quer de conteúdo. 
Estas são as palavras do sacerdote de Ísis, que, no livro undécimo do romance de Apuleio, aponta as causas dos males de Lúcio: as seruiles uoluptates e a curiositas inprospera ${ }^{2}$. Ao longo do romance há diversos avisos da providência contra estas tentações. Significativa é a imagem dinâmica do átrio de Birrena (2.4): a metamorfose de Actéon, vítima da sua própria curiosidade concupiscente (curiosus optutus). Mas o incauto Lúcio, dando largas às seruiles uoluptates, deixa-se arrastar para os braços de Fótis, e, levado pela curiosidade, acaba metamorfoseado em Burro. Assim começam os errores do infeliz até conseguir obter as rosas que lhe devolverão a forma humana.

A novela de Cárite é um exemplo trágico de uma advertência indirecta. A história está organizada em quatro partes, como quatro actos de uma tragédia ${ }^{3}$, que ocorrem em paralelo com a história de Lúcio e têm repercussões na própria fortuna do herói-burro: um primeiro acto representa os lamentos de uma jovem nobre, Cárite, raptada por ladrões no próprio dia do seu casamento, enquanto uma velha ama, que desempenha o papel de confidente, a procura consolar (4.23-27); o segundo é uma tentativa gorada de fuga da donzela e do burro (6.25-32); o terceiro, a salvação inesperada de Cárite, por iniciativa do noivo, que mata os bandidos, e a alegria do reencontro (7.1-14); o quarto, o desenlace - a morte de Tlepólemo à traição, por obra de Trasilo, a vingança de Cárite, o suicídio da protagonista e o de Trasilo (8.1-14).

Os estudiosos têm referenciado nesta novela elementos trágicos, alusões épicas e topoi do romance grego ${ }^{4}$. De facto, além da estrutura e do desenlace, há outros elementos que remetem para o universo da tragédia ${ }^{5}$. Desde logo se diz que era uma donzela nobre - ...uirginem filo liberalem et, ut matronatus eius indicabat, summatem regionis (4.23). Além disso, é uma personagem virtuosa que realiza acções esforçadas, qualidades do $\sigma \pi 0 v \delta \alpha i ̂ s$, referido por Aristóteles, que

2 Vide TAtum, J., "The tales in Apuleius' Metamorphoses" : TAPhA 100 (1969) 487-527, particularmente, 489-491 e 516-517.

${ }^{3}$ Vide BRANDÃo, J. L., "O romance de Cárite: uma tragédia em quatro actos" : Humanitas 47 (1986) 183-195.

${ }^{4}$ Vide Ruiz Sánchez, M. "Lucio en el campo. Observaciones sobre los libros VII y VIII del Asno de oro de Apuleyo" : Emerita 68 (2000) 115-139.

5 Vide TeIXeIra, C., Estrutura da viagem na épica de Virgílio e no romance latino (dissertação de doutoramento), Évora 2003, 356-369, e, da mesma autora, "O sentido do trágico em Apuleio: tradição e/ou ruptura?": Actas do IV Congresso da APLC, Évora, Universidade, 2004, 1-11 
dão à intriga uma certa grandiosidade ${ }^{6}$ : na procura dos seus fins, a jovem mostra uma audácia superior ao seu sexo e idade (6.27), leva a cabo a vingança com masculus animus (8.11) e no final exala a anima uirilis (8.14). Sublinha-se a passagem de uma situação de felicidade à desgraça. Ela própria, na condição de cativa, estabelece um confronto, de sabor euripidiano, entre a fortuna do passado e a desdita do presente, proferindo um discurso que nos lembra o de Hécuba na tragédia homónima ${ }^{7}$ :

'An ego - inquit - misera tali domo tanta familia tam caris uernulis tam sanctis parentibus desolata et infelicis rapinae praeda et mancipium affecta inque isto saxeo carcere <et carnificinae laniena $>$ seruiliter clausa et omnibus deliciis, quis innata atque innutrita sum, priuata sub incerta salutis $<$ spe $>$ inter tot ac tales latrones et horrendum gladiatorum populum uel fletum desinere uel omnino uiuere potero?' (4.24).

'Então eu - disse ela - infeliz, afastada de tão grande casa, de tão nobre familia, de tão queridos escravos, de tão veneráveis pais e presa de tão funesto rapto, transformada em mercadoria e encerrada como escrava neste cárcere de pedra e açougue de tormentos, privada de todos os prazeres, em que nasci e fui criada, poderei, por acaso, animada por uma esperança vã de salvação, entre tal número e tal tipo de ladrões e horrivel povo armado de espadas, deixar de chorar ou sequer continuar a viver?'

Mas, no momento em que afirma a incapacidade para suportar as desgraças presentes, não pode imaginar que as futuras serão ainda maiores. Tal como Hécuba, também Cárite experimentará a dor da ruína integral da sua família. No início do livro oitavo, um escravo traz a notícia da morte não só da jovem esposa, mas de toda a casa ( $I s$ de eius exitio et domus totius infortunio mira ac nefanda).

Para Hécuba e para Cárite, quanto maior foi a felicidade, mais insuportável é o infortúnio. Ora a $\alpha i \sigma \chi \rho \alpha \grave{~} \tau u ́ \chi \eta^{8}$, que, segundo Taltíbio, explica a passagem da soberana de Tróia da felicidade à desgraça, é representada no romance de Apuleio pela Fortuna caeca, que persegue Lúcio até ao décimo livro. À semelhança de Cárite, também ele, ao saber que fora acusado do roubo da casa de Milão, onde estava hospedado no momento da metamorfose, compara a situação presente com a felicidade passada e atribui os azares à arbitrariedade do destino:

Haec eo narrante ueteris fortunae et illius beati Lucii praesentisque aerumnae et infelicis asini facta comparatione medullitus ingemebam

\footnotetext{
${ }^{6}$ Po. 6.1449 b $9-10 ; 22$ ss.

${ }^{7}$ Euripides, Hec. 154-175.

${ }^{8}$ Taltíbio descreve a amplitude da queda da soberana de Tróia: Hec. 492-500.
} 
subibatque me non de nihilo ueteris priscaeque doctrinae uiros finxisse ac pronuntiasse caecam et prorsus exoculatam esse Fortunam, quae semper suas opes ad malos et indignos conferat nec unquam iudicio quemquam mortalium eligat, immo uero cum is potissimum deuersetur quos procul, si uideret, fugere deberet, quodque cunctis est extremius uarias opiniones, immo contrarias nobis attribuat, ut et malus boni uiri fama glorietur et innocentissimus contra noxiorum more plectatur (7.2).

Enquanto ele narrava, eu, ao comparar a Fortuna de outrora e aquele Lúcio feliz com os sofrimentos presentes e o infeliz asno que agora era, gemia profundamente e ocorria-me pensar que não foi sem razão que os velhos sábios de tempos recuados imaginaram e representaram a Fortuna cega e totalmente privada de olhos, uma vez que reserva sempre os seus favores para os maus e indignos e nunca elege um dos mortais com base num justo juízo. Pelo contrário, prefere a companhia daqueles que, se pudesse ver, de longe deveria evitar. O pior de tudo é que distribui entre nós a reputação de forma tão incerta, ou melhor, tão equívoca, que o mau se vangloria de ter a fama de um homem honrado e o mais inocente, pelo contrário, é castigado como um criminoso.?

Acusado de um crime nefando contra a hospitalidade - um parricidium - Lúcio ainda tentou defender-se (7.3). Mas, amordaçado pela fisiologia do burro, quando ia a clamar 'non feci', non conseguiu repetir senão 'non non'. A frustração de Lúcio traduz bem a impotência humana perante as ciladas da Fortuna caeca.

Nada fazia supor o triste desenlace da história de Cárite. Tratavase de uma jovem mulher que, como tantas outras, estava ligada ao noivo pelos mútuos laços de uma sancta caritas (4.25) e se preparava para celebrar os esponsais. Depois de libertada do cativeiro em que se encontrava, através da heróica intervenção do noivo, tudo parecia indicar que seria afortunada. Mas, a par da acção da Fortuna caeca, uma espécie de hamartia se pode vislumbrar na actuação do casal, quando recebe na intimidade do lar o antigo pretendente à mão de Cárite. $\mathrm{O}$ retrato que o mensageiro faz de Trasilo sublinha a natureza dos seus vícios: a despeito da origem nobre, levava uma vida de devassidão, por tavernas e meretrizes, embriaguez, associação com malfeitores e crimes de sangue - um emulador do Catilina de Salústio. ${ }^{10}$ Depois de se

${ }^{9}$ Parece ainda ser para sublinhar a acção da Fortuna que o escravo mensageiro, referindo-se à morte de Cárite, emprega a expressão casus grauissimus (8.1): isto é, o pesado destino que caiu sobre a patroa.

${ }^{10}$ Met. 8.1: Erat in proxima ciuitate iuuenis natalibus praenobilis quo clarus et pecuniae fuit satis locuples, sed luxuriae popinalis scortisque et diurnis potationibus exercitatus atque ob id factionibus latronum male sociatus nec non etiam manus infectus humano cruore, Thrasyllus nomine. Idque sic erat et fama dicebat. Para Walsh, P. G., The Roman novel, Cambridge, Un. Press, 1970, 164, trata-se de um eco claro do retrato de Catilina em Salústio. 
juntar à turba dos que vêm felicitar o casal, é através da dissimulação que Trasilo consegue ser recebido na intimidade da família ${ }^{11}$. Os traços de carácter que levaram Cárite a rejeitá-lo, deviam fazer suspeitar da sinceridade de uma tão radical mudança de comportamento. Mas, por ignorância e por nobreza de alma, Cárite e Tlepólemo acolhem como amicus fidelissimus aquele que virá a ser a causa da sua destruição. Uma decisão aparentemente acertada, e mesmo louvável, estimula a progressão para a catástrofe. Trata-se, portanto, de uma hamartia enquanto «erro de juízo», como a define Maria do Céu Fialho ${ }^{12}$.

Um outro erro se manifesta na acção de Tlepólemo. Cárite não permitia que o marido perseguisse animais perigosos (8.4: nec enim Charite maritum suum quaerere patiebatur bestias armatas dente uel cornu). Mas ele, esquecido da advertência da esposa, dá ouvidos a Trasilo que o instiga a caçar um javali feroz (8.5) e, sem o saber, oferece ao rival a oportunidade de consumar o crime que este projectava desde o momento em que fora preterido (8.2).

O conto traduz a incapacidade do homem para determinar os seus próprio fins. Aqui reside a beleza e o terror da história: por representar as limitações humanas, quem a ouve sente-a como potencialmente sua. Nesse sentido, o escravo, que traz a notícia da morte dos amos, acentua o carácter modelar dos acontecimentos (8.1):

'Sed ut cuncta noritis, referam uobis a capite quae gesta sunt quaeque possint merito doctiores, quibus stilos fortuna subministrat, in historiae specimen chartis inuoluere'.

'Para ficarem a saber tudo, vou narrar-vos os sucessos desde o início, e tais factos bem merecem que os mais doutos, a quem a sorte favorece com o dom do estilo, os possam fixar por escrito, à maneira de um romance'.

Reacção semelhante tem o narrador principal: depois de ouvir a história de Cupido e Psique, que a velha conta para consolar a jovem, Lúcio-burro lamenta não ter à mão tabuinhas para registar tam bella fabella (6.25). Mas enquanto este conto tem um fim feliz, a história de Cárite termina em catástrofe. Um relato belo com um desenlace trágico assume um carácter mais forte de aviso. Além disso, Psique é um arquétipo mítico; Cárite está mais próxima do comum dos mortais.

${ }^{11}$ Met. 8.2: ... turbae gratulantium exultans insigniter permiscuit sese salutique praesenti ac futurae suboli nouorum maritorum gaudibundus ad honorem splendidae praosapiae inter praecipuos hospites domum nostram receptus, occultato consillio sceleris, amici fidelissimi personam mentiebatur.

${ }_{12}$ Aristóteles, Po. 1453 a 10. Fíalho, M. C., "Algumas considerações sobre o homem trágico" : Biblos 53 (1977) 375-388, particularmente 383-384. 
Outro elemento da tradição épica e trágica presente no romance é a visão onírica ${ }^{13}$. A protagonista é receptora de dois sonhos. No primeiro, Cárite, na caverna dos ladrões, revive o seu próprio rapto e vê o marido ser morto por um dos raptores $(4.27)^{14}$. Na altura, a velha, que assume o papel de confidente, desvaloriza o facto e considera-o até presságio de felicidade (4.27):

'Bono animo' esto, mi erilis, nec uanis somniorum figmentis trerreare. Nam praeter quod diurnae quietis imagines falsae perhibentur, tunc etiam nocturnae uisiones contrarios euentus nonmumquam pronuntiant. Denique flere et uapulare et nonnumquam iugulari lucrosum prosperumque prouentum nuntiant, contra ridere et mellitis dulciolis uentrem saginare uel in uoluptatem ueneriam conuenire tristitie animi languore corporis damnisque ceteris uexatum iri praedicabunt'.

'Tem coragem, minha jovem senhora, e não te deixes atemorizar pelas vãs aparências dos sonhos. Se as visões do sono diurno são consideradas falsas, também as visões nocturnas pressagiam por vezes resultados contrários. Portanto, chorar, ser açoitado e às vezes ser degolado anunciam um resultado vantajoso e próspero; pelo contrário, rir, encher a barriga de doces guloseimas ou entregar-se aos prazeres de Vénus, significará que te irão atormentar a tristeza, a enfermidade e outras desgraças'.

A teoria da ama parece evocar situações trágicas em que o sonho surge sob a suspeita de ser ilusório. Lembra, em certa medida, o cepticismo de Clitemnestra, ao dar a notícia da tomada de Tróia, no primeiro episódio do Agamémnon de Esquilo ${ }^{15}$, ou de Jocasta, no Rei Édipo de Sófocles, quando sugere que já muitos sonharam que casavam com as mães, sem se preocuparem demasiado com isso (980-983).

Mas os sonhos tendem a ser considerados enganosos se anunciam alegrias, como o de Menelau, em que Helena the aparece a chorar ( $\mathrm{Ag}$. 420-426). A questão centra-se em interpretar o seu verdadeiro

${ }^{13}$ Vide LEVI, E., "Le théâtre et le rêve: le rêve dans le théâtre d'Eschyle" : Théâtre et spectacles dans l'antiquité. Actes du Colloque de Strasbourg, 5-7 novembre 1981, Université de Sciences Humaines de Strasbourg, 141-168; BARONE, C. "L'apparizione dello spettro nella tragedia greca" : Aufidus 37 (1999) 7-44.

${ }^{14}$ MignognA, E., "Carite ed Ilia: sogni di sogni" : GCN 7 (1996) 95-102, vê no episódio ecos do sonho de Dido, na Eneida de Vírgílio (4.465-468), e do sonho da vestal ília, nos Anais de Énio (fr. 1, 29 Sk., 34-50).

${ }^{15}$ Ag. 273-275: Corifeu: .... Tens alguma prova disso? / Clitemnestra: Tenho, é evidente que sim. A menos que um deus me engane... / Corifeu: Estarás, por acaso, a fiar-te em visões persuasivas de sonhos? / Clitemnestra: Pouco crédito dou às fantasias dum espirito ensonado. Tradução de PULQUÉRIO, M. O., Coimbra, INIC - CECH, 1985, 24-25. Outros exemplos da ilusão do sonho em Ésquilo: Ag. 489-492, Ch. 288. 
significado $^{16}$. Na Ifigénia entre os Tauros de Eurípides (42-66), a protagonista considera como sinal da morte de Orestes um sonho que se revela favorável. De forma geral, o receptor do sonho procura esconjurar o mau agoiro com ritos apotropaicos, como Clitemnestra, nas Coéforas (esta sonhara que dava à luz e amamentava uma serpente, presságio que Orestes refere imediatamente à sua pessoa) (523-550). Uma vez que o sonho de Cárite é premonitório de infortúnio, a interpretação contrária, aventada pela velha, deve-se certamente ao facto de esta se empenhar no papel de consoladora. Por outro lado, baseia-se na ideia de que os sonhos podem resultar da ansiedade e do desejo, e são por isso reveladores e amplificadores de sentimentos profundos $^{17}$.

Apesar disso, a confidente acerta, mas só em parte: a sua interpretação é corroborada pelos acontecimentos mais imediatos, pois Cárite em breve será libertada, devido a uma bem sucedida intervenção do marido. Também Clitemnestra, na Electra de Sófocles, ao receber a notícia, falsa, da morte de Orestes, vive na ilusão da libertação da ameaça latente no sonho que, simbolicamente, anunciava o regresso do filho (através da vitalidade da vergôntea que brotava do ceptro plantado por Agamémnon na lareira ${ }^{18}$. A despeito da diferença fundamental - Clitemnestra vai ser castigada por um crime que cometeu; Cárite é vítima inocente - salva-se o paralelismo da situação. Se a primeira é vítima do dolo de Orestes, a última é vítima do dolo do antigo pretendente. Para a jovem, a desgraça prevista acaba por se efectivar finalmente na morte de Tlepólemo: crime encoberto sob a capa de acidente de caça. O ladrão que o mata no sonho simboliza Trasilo, pois, também este, na descrição feita pelo escravo mensageiro, aparece, como vimos, associado a bandos de ladrões $(8.1)^{19}$.

A verdade sobre a morte de Tlepólemo é reposta através de um segundo sonho, em que o próprio vem revelar à esposa que foi a lança de Trasilo que o matou, e não apenas os gorgomilos do javali, ao

${ }^{16}$ Etéocles só compreende o sonho (Sept. 709-711) em que partilhava os bens paternais (alusão às maldições de Édipo), quando se vê envolvido no duelo fratricida com Polinices. Vide LEvi, E., "Le théâtre et le rêve..." cit. 158-159.

17 Como afirma Levi, E. "Le théâtre et le rêve..." cit. 160-168. É a saudade (pothos) que faz Menelau sonhar com Helena ( $\mathrm{Ag} .414-415)$. Clitemnestra finge ter visto em sonhos os sofrimentos do marido pra provar o seu amor por ele ( $\mathrm{Ag}$. 893-894).

${ }^{18}$ Vide Fialho, M. C., Luz e trevas no teatro de Sófocles, Coimbra, INIC $\mathrm{CECH}, 1992,168$ ss.

i9 Vide Frangoulidis, S. A., "The sommus funestus and sommus uamus of Charite: Apuleius, Met. 4.27 (95.16)" : Latomus 52 (1993) 105-111. 
mesmo tempo que a instiga a rejeitar as núpcias com o sacrílego (8.8). Assim, a segunda experiência onírica de Cárite, além de esclarecer o sentido do primeiro sonho, enriquece o enredo com uma nova orientação no sentido da vingança. A aparição nocturna recorda, em parte, o sonho das Erínias nas Euménides (94-161) ${ }^{20}$. Há alguma semelhança na situação: o espectro de Clitemnestra exorta as terríveis deusas a contemplarem as suas feridas (103); a sombra de Tlepólemo apresentase massacrada e horrivelmente desfigurada e, no seu discurso, também refere as feridas ${ }^{21}$. Ambos têm como alvo o seu assassino, mas, ao contrário de Clitemnestra, Tlepólemo não reclama o castigo do agressor. O resultado, no entanto, acaba por ser, de certo modo, semelhante, uma vez que é este sonho que levará Cárite a preparar a vingança, assumindo o papel de uma Fúria.

$\mathrm{Na}$ verdade, esta visão aproxima-se mais do fantasma de Polidoro, que, na Hécuba de Eurípides, vem expor o crime de Polimestor contra as regras da hospitalidade, sem pedir mais do que tributos fúnebres $(10 ; 25-27)^{22}$. Se compararmos a sucessão dos acontecimentos, constatamos que há semelhança flagrante na reacção das protagonistas às mortes - delírio báquico ${ }^{23}$-, na estratégia dolosa da vingança e na forma de a levar a cabo.

Tal como Hécuba, Cárite delineia um plano para atrair o assassino a uma armadilha e serve-se dos vícios do inimigo para preparar o engodo: a cupidez de ouro de Polimestor permite atraí-lo sem os guarda-costas à tenda onde será atacado; a libido e inclinação para a bebida de Trasilo colocam-no à mercê das mãos vingativas da jovem viúva.

O estratagema de Cárite é semelhante ao que, atrás (7.5-12), o noivo empregara para a libertar das mãos dos raptores. Tlepólemo e Cárite prometem aos antagonistas aquilo que eles querem ouvir. $\mathrm{O}$ primeiro faz-se passar por Hemo, um suposto ladrão ${ }^{24}$, também Trácio

${ }^{20}$ Vide LĖVI, E. "Le théâtre et le rêve..." cit. 148-149; BARONE, C. "L'apparizione dello spettro nella tragedia greca" cit. 26-32.

21 Met. 8.8: Tunc inter moras umbra illa misere trucidati Tlepolemi sanie cruentam et pallore deformem attollens faciem quietem pudicam interpellat uxoris. (...) 'Vulnera illa...

${ }^{22}$ Há divergência entre os críticos sobre se se trata de um fantasma ou de um sonho. Vide BARONE, C. "L'apparizione dello spettro nella tragedia greca" cit. 33-42.

${ }^{23}$ Met. 8.6: cursuque bacchata furibundo; Euripides, Hec. 686-687: Baccheion nomon

${ }^{24}$ Nome associado a "sangue" e a uma famosa montanha da Trácia. Um levantamento de ocorrências do nome 'Hemo' em contextos literários e míticos, na 
como Polimestor. Depois de inventar a história da destruição do seu bando, por acção de uma mulher casta, Plotina, o jovem oferece aos ladrões o que ele chama um "dote" e promete trazer-lhes grandes riquezas, se o aceitarem como chefe ${ }^{25}$. Cárite começa por iludir Trasilo com promessas de casamento, a realizar depois do luto, para depois fingir aceitar um encontro imediato, na condição de ser secreto ${ }^{26}$, aparato que muito agrada ao pretendente ${ }^{27}$.

Tlepólemo e, depois, Cárite servem-se do vinho para colocarem o inimigo à sua mercê. $\mathrm{O}$ modelo é épico: recorda Ulisses na caverna do Ciclope $^{28}$. O jovem simula um banquete sacrificial a Marte Comes (Lúcio suspeita do emprego de um soporífero); Cárite finge atrasar-se e envia a ama com uma jarra de vinho drogado. O efeito sobre os ladrões e sobre Trasilo não se faz esperar: como outrora Tróia, ficam sepultados no vinho e no sono ${ }^{29}$.

toponímia e na antroponímia - associações que não escapariam à erudição de Apuleio -, pode ler-se em Humans JR, B. L. "Apuleiana Groningana V. Haemus, the bloody brigand (or: what's in an alias)" : Mnemosyne s. 4, 31 (1978) 407-414.

${ }^{25}$ Met. 7.8: 'En - inquit - istam sportulam, immo uero dotem collegio uestro libens meque uobis ducem fidissimum, si tamen non recusatis, offero breui temporis spatio lapideam istam domum uestram facturus auream'. FRANGOULIDIS, S. A., "Selfimitation in Apuleius' tales of Tlepolemus/Haemus and Thrasyleon" : Mnemosyne 47 (1994) 337-348, põe em evidência a correspondência estrutural e temática entre o conto de Tlepólemo / Hemo e o de Trasileão (4.13-21): este penetra na casa de Demócares vestido com uma pele de ursa

${ }^{26}$ Met. 8.10: ... quoad simulanter reuicta Charite suscipit: 'Istud equidem certe magnopere deprecanti concedas necesse est mihi, Thrasylle, ut interdum taciti clandestinos coitus obeamus nec quisquam persentiscat familiarium, quoad reliquos dies metiatur annus.' ... 'Sed heus tu - inquit Charite - quam probe ueste contectus omnique comite uiduatus prima uigilia tacitus fores meas accedas unoque sibilo contentus nutricem istam meam opperiare, quae claustris adhaerens excubabit aduentui tuo. Nec setius patefactis aedibus acceptum te nullo lumine conscio ad meum perducet cubiculum'.

${ }^{27}$ Met. 8.10:... Promissioni fallaciosae mulieris oppressus subcubuit Trasyllus et prolixe consentit de furtiuo concubitu noctemque et opertas exoptat ultro tenebras uno potiundi studio postponens omnia. 8.11: Placuit Thrasyllo scaena feralium nuptiarum.

28 Vide Frangoulidis, S. A., "Charite dulcissima: a note on the nameless Charite at Apuleius' Metamorphoses 7.12 (163.10)" : Mnemosyne 44 (1991) 387-394. Tal como Ulisses na caverna do ciclope, a misera não tem nome até estar prestes a ser salva. Mas as diferenças de tratamento em relação a Homero e Virgílio levam este autor a falar, um ano mais tarde, de inversão épica: vide Frangoulidis, S. A., "Epic inversion in Apuleius' tale of Tlepolemus/Haemus" : Mnemosyne 45 (1992) 60-74.

${ }^{29}$ Repare-se nos ecos internos. Met. 7.12: Et hercules suspicionem mihi fecit quasi soporiferum quoddam uenenum cantharis immisceret illis. Cuncti denique, sed prorsus omnes uino sepulti iacebant, omnes pariter mortui. 8.11: Tunc amus de iusso dominae blandiens ei furtim depromptis calicibus et oenophoro, quod immixtum uino 
Antes de completarem a tarefa ambos proferem um discurso. O de Tlepólemo é breve e dirigido a Cárite (7.12): 'Bono animo es - inquit - Charite dulcissima; nam totos istos hostes tuos statim captiuos habebis' ('Coragem - disse ele — minha tão doce Cárite; pois vais ter imediatamente captivos todos estes inimigos'). O de Cárite, pelo contrário, é um longo discurso de vingança dirigido a Trasilo, em que a ironia sugere a raiva (8.12): 'En ... fidus coniugis mei comes, en uenator egregius, en carus maritus.... Quiesce securus, beate somniare' ('Eis-te aqui, ... fiel companheiro do meu marido, ilustre caçador, eiste meu caro esposo... dorme descansado, bons sonhos!'). Na verdade é um solilóquio; o destinatário está adormecido: serve apenas para ela poder exteriorizar os sentimentos que teve de dissimular, enquanto executava o seu secreto plano de vingança. O desfecho é semelhante ao do estratagema de Hécuba na referida peça de Eurípides ${ }^{30}$. Se Telepólemo ofereceu à noiva os inimigos cativos, Cárite oferece aos Manes do falecido o sangue dos olhos do seu assassino e condena Trasilo à sorte de um Édipo. É notório o jogo de contrastes entre luz e trevas, mundo dos vivos e mundo dos mortos:

'Lumen certe non uidebis, manu comitis indigebis, Chariten non tenebis, nuptias non frueris, nec mortis quiete recreaberis nec uitae uoluptate laetaberis, sed incertum simulacrum errabis inter Orcum et solem (...) At ego sepulcrum mei Tlepolemi tuo luminum cruore libabo et sanctis manibus eius istis oculis parentabo. (...) Vltrices habebis pronubas et orbitatem comitem et perpetuae conscientiae stimulum' (8. 12).

'A luz não a verás, terás necessidade do braço de um companheiro, Cárite não a possuirás, as núpcias não as gozarás, com o descanso da morte não te reconfortarás, nem com o prazer de viver te alegrarás, mas, como sombra vacilante, hás-de errar entre o Orco e o sol. (...) Farei uma libação com o sangue dos teus olhos sobre o túmulo do meu querido Tlepólemo e imolarei a tua vista em honra dos seus sagrados Manes. (...) Terás as Fúrias como madrinhas de casamento, a cegueira por companhia e um eterno aguilhão na consciência'.

Parece haver algo de excessivo nesta declaração. A audácia contrasta com fragilidade da misera no covil dos ladrões (4.24) e com a Charite dulcissima (7.12) das palavras de Tlepólemo. Uma metamor-

soporiferum gerebat uenenum. crebris potationibus auide ac secure haurientem mentita dominae tarditatem, quasi parentem adsideret aegrotum, facile sepeliuit ad somnum. A expressão uino sepultus é um eco de Virgilio, Aen. 2.265: inuadunt urbem somno uinoque sepultam (cf.. 3.630: nam simul expletus dapibus uinoque sepultus). Vide FrangOulidis, S. A., "Epic inversion in Apuleius..." cit. 70.

${ }^{30} \mathrm{Em}$ ambas as obras os assassino é cego com um objecto de uso feminino: Met. 8.13: acu crinali capite deprompta; Hec. 1170: $\pi$ ó $\pi \alpha$ s. 
fose semelhante à de Hécuba ${ }^{31}$ se opera em Cárite ${ }^{32}$ : de Graça transforma-se em Fúria insana. O narrador vai assinalando a mudança. Ao saber da morte do marido corre como uma Bacante em delírio (cursuque bacchata furibundo) e lamenta a morte com uma insana uox (8.6); lança urros animalescos (ferinos mugitus iterans), perante as propostas de Trasilo (8.8); desfaz em pedaços a túnica interior e martiriza os braços, ao acordar do sonho que revela o crime (8.9). Depois de cegar Trasilo, corre como uma Fúria pela cidade, empunhando a espada do marido nas mãos insanas (cursu furioso proripit... uaesanis... manibus); ao morrer, exala uma alma que o narrador classifica de viril (proflauit animam uirilem) (8.14).

Pressente-se ainda uma certa arrogância na forma como faz das virtudes a sua bandeira (8.13) e demasiada obstinação na ideia do suicídio. Assim, arvora-se em mártir da sua própria castidade:

'Abicite - inquit - importunas lacrimas, abicite luctum meis uirtutibus alienum. Vindicaui in mei mariti cruentum peremptorem, punita sum funestum mearum nuptiarum praedonem. Iam tempus est ut isto gladio deorsus ad meum Tlepolemum uiam quaeram'

'Fora - disse ela - com as lágrimas importunas; fora com o luto impróprio das minhas virtudes! Vinguei-me do sanguinário assassino do meu marido; castiguei o funesto predador do meu casamento. Agora é tempo de, por esta espada, procurar o caminho para descer até ao meu Tlepólemo'.

A metamorfose de Cárite leva-a à aniquilação. Na caverna dos ladrões estava incógnita e só passa a ter nome em presença do marido. A partir do momento em que o perde, deixa de ter razão de existir. Mas, no final, sugere-se que Cárite procura na morte os fins que não atingiu em vida.

Apesar de o acto de cegar e a auto-imolação no túmulo do amado serem, como nota Walsh, reminiscências das grandes tragédias sofocleanas $^{33}$, as reviravoltas da Fortuna, o pathos, o realismo, a fuga à unidade de acção e a transformação no carácter da protagonista lembram mais Eurípides. Mas o final da narrativa não é tão pessimista como possa parecer e deve ser interpretado no conjunto das Metamorfoses de Apuleio. O sentido trágico da história não se esgota em si mesmo. A dimensão estética e patética está ao serviço da ética. A história apregoa a defesa de uma moral sexual que ganha terreno durante

${ }^{31}$ De vítima débil e incapaz de reagir transforma-se em vingadora desapiedada. Vide BARONE, C. "L'apparizione dello spettro nella tragedia greca" cit. 41-42.

${ }^{32}$ Vide TAtum, J., "The tales in Apuleius' Metamorphoses" cit. 517-518.

${ }^{33}$ WALSH, P. G., The Roman novel cit. 164. 
o império ${ }^{34}$. Está em causa a apologia da castidade e da preservação dos laços matrimoniais, como mostra a história de Plotina, que decide acompanhar o marido no exílio ${ }^{35}$, e o conto de Amor e Psique. Insistese na ideia da mulher de um só marido, ideal que Cárite incarna até às últimas consequênciaș. Trasilo, o elemento perturbador desta ordem, é castigado como nuptiarum praedo.

Mas não se apregoa apenas de uma moral imanente: parece basear-se em preceitos da religião isíaca, sugeridos no discurso do sacerdote no último livro do romance (11.15). Isís é venerada no império como protectora da família e do casamento. A história de Cárite e Tlepólemo tem sido interpretada como mimese da de Ísis e Osíris, pois também este foi morto por Set. Trata-se possivelmente da influência dos mistérios helenístico-romanos ligados à renovação da vida. Nesse sentido parece apontar também o culto prestado ao defunto marido, representado sob a forma de Liber-Baco (8.7) ${ }^{36}$.

O facto de Cárite, ao ser sepultada, se tornar a perpetua coniux de Tlepólemo (8.14) remete para a ideia de uma religião de salvação ${ }^{37}$. A crença na redenção post mortem permite contrabalançar a desordem introduzida na vida terrena pela Fortuna caeca e pela perversidade humana. Mesmo o elemento maligno, Trasilo, desperta no final alguma compaixão, e, de certo modo, redime-se in extremis ao punir-se a si próprio: encerra-se no túmulo para morrer de inanição, como vítima voluntária para os Manes (8.14).

Lúcio não está ainda em condições de compreender os avisos da providência. Psique, protótipo mítico de Cárite, castigada pela sua curiosidade $(5.23)^{38}$, tem de fazer um percurso ascético que a redime.

${ }^{34}$ Vide VEYNE, P. “A sociedade romana", Lisboa, Edições 70, 1990, 157 ss.

${ }^{35} \mathrm{Um}$ exemplo de fidelidade conjugal com paralelos na vida política do século primeiro, como o das duas Árrias (a esposa de Cecina Peto e a de Trásea Peto) e Fânia (esposa de Helvídio Prisco): cf. Plínio, Ep. 3.11, 16; 7.19; Tácito, Hist. 1.3.

${ }^{36}$ Embora, segundo Hijmans jr, B. L., "Charite worships Tlepolemus-Liber" : Mnemosyne 39 (1986) 350-364, falte uma ligação evidente entre Baco e Osíris. Este autor demonstra, no entanto, que existem vários traços comuns entre Tlepólemo e o deus Liber, em cujos mistérios o próprio Apuleio seria iniciado (cf. Apol. 55.8). Há no texto outras referências míticas, explícitas ou implicitas, ligadas à ideia de vida depois da morte e a mistérios, como é o caso de Átis (4.26) e de Adónis (Tlepólemo morto pelo javali).

${ }^{37}$ Vide TeiXeira, C., Estrutura da viagem ... cit. 367-369, e "O sentido do trágico em Apuleio: tradição e / ou ruptura?" cit. 1-11.

${ }^{38}$ Sobre a curiositas como conceito primário da moral de Apuleio, vide COOPER, G., "Sexual and ethical reversal in Apuleius: the Metamorphoses as anti-epic" : Studies in Latin literature and history, a cura di DEROux, C., Bruxelles, Latomus - Les Belles Lettres, II, 1980, 436-460, particularmente 453 ss. 
No entanto o herói, ou anti-herói, transformado em burro pelo mesmo erro, capta apenas o valor estético da bella fabella, sem perceber que se trata do modelo da sua própria ascese. A união de Cupido e Psique simbolizam a harmonia entre o desejo e a alma, que Lúcio deverá atingir no final.

É no papel de espectador que Lúcio / burro assiste ao desenrolar dos últimos acontecimentos da vida de Cárite. Na linha da tradição trágica, cabe ao mensageiro relatar o morticínio. Lúcio parece associar a sorte da jovem à sua própria desgraça, uma vez que com ela partilhou provações, como ele próprio sublinha (...puellae illius, quae mecum apud latrones pares aerumnas exanclauerat ${ }^{39}$. Devia antes temer a sorte de Trasilo. O escravo mensageiro, ao referir-se à ruina cupidinis, na qual se precipitava o pretendente de Cárite, faz reflexões que soam a advertências: Quidni, cum flamma saeui amoris parua quidem primo uapore delectet, sed fomentis consuetudinis exaestuans inmodicis ardoribus totus amburat homines ${ }^{40}$ ('E porque não, se a chama do amor cruel, débil, a princípio, nos deleita com o seu calor, mas fomentada pelo hábito, se eleva num incêndio desenfreado que abrasa todos os homens?'). E mais à frente apresenta o resultado da furiosa libido: Spectate denique, sed oro, sollicitis animis intendite, quorsum furiosae libidinis proruperint impetus (8.3) ('Ora reparem então, por favor, considerem com a maior atenção até onde podem levar os impulsos de um louco desejo!'). Note-se que Lúcio não refreia a lascívia mesmo relação a Cárite: quando a vê entrar na caverna, descreve-a como concupiscenda até para o burro que ele era (4.23) e, quando a transporta no dorso, durante a fuga frustrada, aproveita para, disfarçadamente, lhe beijar os pés (6.28).

Também discurso proferido por Cárite contra o assassino do marido soa como um aviso a Lúcio. Se este persistir nos seus erros, poderá ter o mesmo destino que Trasilo: vaguear no mundo das trevas. No caso de entendermos o romance como apologético na sua totalidade, apresentam-se ao protagonista dois caminhos opostos: o de Cárite e Tlepólemo, isto é de Ísis e Osíris, e o de Trasilo e de Set; o da redenção e o da perdição, o da luz e o das trevas ${ }^{41}$. Mas, além do

39 Met. 8.1. O termo aerumna é frequentemente usado para designar as tribulações de Lúcio (cf. $3.29 ; 7.2 ; 7.16 ; 7.27 ; 8.26$. Vide TATUM, J., "The tales in Apuleius' Metamorphoses" cit. 489 n.10.

${ }^{40}$ Met. 8.2. Cf. TAtum, J., "The tales in Apuleius' Metamorphoses" cit. 517.

${ }^{41}$ No livro 11, Ísis manifesta-se na lua. Osíris aparece assimilado ao sol em Plutarco: vide BRENK, F.E., "In the Image, Reflection and Reason of Osiris. Plutarch 
mérito e das escolhas individuais, há que contar com a graça divina. Como predestinado, Lúcio será resgatado das tribulações (aerumnae) pela providência de Ísis. Depois de dez livros em que impera a Fortuna cega, o livro onze é caracterizado pelo triunfo da Fortuna clarividente $^{42}$, que representa a libertação do terror resultante da impotência do homem perante a tyche, como se depreende das palavras do sacerdote:

'Nam in eos, quorum sibi uitas <in> seruitium deae nostrae maiestas uindicauit non habet locum casus infestus. Quid latrones, quid ferae, quid seruitium, quid asperrimorum itinerum ambages reciprocae, quid metus mortis cotidianae nefariae Fortunae profuit?' (11.15)

'É que contra aqueles, cujas vidas foram reivindicadas pela majestade da nossa deusa para o seu serviço, nada podem os acontecimentos adversos. Ladrões, animais selvagens, escravatura, andanças por duríssimas veredas, o medo diário da morte: o que é que isso aproveita à abominável Fortuna.'

Nesta perspectiva, também a tragédia de Cárite, que o protagonista acompanha de perto, adquire um novo significado. Do ponto de vista do crente, a "Graça", não é desafortunada porque se manteve fiel aos princípios da deusa. Tal como Ísis e Osíris ou Cupido e Psique, Cárite e Tlepólemo não são separados pela morte. E o sustentáculo da união do casal é o amor puro (sancta caritas), por oposição à furiosa libido e às seruiles uoluptates.

Sem Ísis, a vida do homem é trágica e desprovida de esperança: nos dez primeiros livros das Metamorfoses, o homem está sujeito às tribulações devidas à perversidade humana e distribuídas arbitrariamente pela Fortuna caeca. Mas, de acordo com o discurso do sacerdote no livro 11, as provações de Lúcio inserem-se no seu processo ascético. A tragicidade da existência humana dá então lugar à esperança; ao jugo da necessidade sucede a providência divina; ao medo e à morte sucede a graça e a redenção - ideias também desenvolvidas, numa perspectiva monoteísta, pelo cristianismo florescente.

and the Egyptian Cults" : PÉrez Jiménez, A. - CASAdesús Bordoy, F. (eds.), Estudios sobre Plutarco: misticismo y religiones mistéricas en la obra de Plutarco (Actas del VII Simposio Español sobre Plutarco, Palma de Mallorca, 2-4 de noviembre de 2000), Madrid, Ediciones Clásicas, 83-98.

${ }^{42}$ Met. 11.15: In tutelam iam receptus es Fortunae, sed uidentis, quae suae lucis splendore ceteros etiam deos illuminat. (...) En ecce pristinis aerumnis absolutus Isidis magnae prouidentia gaudens Lucius de sua Fortuna trumphat. 